\title{
Street Children: Effects and Survival Strategies the Case of West Showa Zone in Ambo Town, Ethiopia
}

\author{
Alemneh Birhanu \\ Department of Social Work, College of Social Science and Humanities, \\ Ambo University, Ethiopia
}

Received: July 13, 2019 Accepted: August 17, 2019 Published: August 19, 2019

doi:10.5296/ijsw.v6i2.15117ＵRL: https://doi.org/10.5296/ijsw.v6i2.15117

\begin{abstract}
The purpose of this study was to investigate the effects of Street Children and their survival Strategies in Ambo town. The study employed qualitative research approach and purposive sampling technique. The sample size for this study was 27 participants in which 17 of them participated in an interview and 10 participated in focus group discussion guided by semi-structured instruments. The finding revealed that children who are joined on the street is due to various reasons such as poverty, family breakdown, migration, looking for jobs, abuse by parents or guardians, peer pressure and expectation of positive life. The result also showed that research participants are facing numerous social problems ranging from sexual abuse, verbal abuse, physical abuse, engagement in drug use, prostitutions, discrimination and different health challenges because of their living condition and inaccessibility to medical services. There should be new strategies that could be taken hand in hand between concerned actors to bring into attention and address the problems of street children in particular manner.
\end{abstract}

Keywords: Street children, Effects, Survival strategies

\section{Introduction}

\subsection{Background of the Research}

The observable fact of street children is swiftly becoming one of the global epic proportions whereby many countries have started to look at it as one of the factors that hinder development. According to UNICEF definition in (2012), Street children are children who are under 18 years of age and belong to the following two categories. Children on the street are those children who live on the street for certain period of the day and return home at any given time and Children of the street are those children whose common living place is on the street. UNICEF's annual State of World's Children reports in (2012) has highlighted the extremely difficult circumstances in which children live and work on the streets. Poverty is the major cause, exacerbated by drought, AIDS, rapid urbanization and family violence and 
breakdown. These and other various reasons force children to go to the street life to try to find solution for those challenges they faced which leads to the phenomenon of street children.

\subsection{Problem Statement}

The level and magnitude of the problem have been increasing through time as a result of street children become a major character of nearly every city and town of Ethiopia (Adugna, 2006). Numerous factors such as break down of social network, drought and famine, armed conflict, rural-urban migration and rapid urbanization that is now going on in most parts of the country are the main causes that expose children to street life. Despite many similarities shared by most urban centers of the country, streets among children in Ethiopia and the problems they face vary from one urban center to another with Addis Ababa taking the lead followed by Adama in Oromia, Gonder in Amhara regional state and Awassa in Southern Nation and Nationalities regional state Forum for Street Children, (2003). According to Mekonnen (2011), streets is becoming one of the major challenges of all urban areas of Ethiopia.

Children in Oromia regional state constitutes $46 \%$ of the total population of the country, and according to research conducted in Adama by Girmay, (2007), out of this number, $11.6 \%$ are homeless which accounts for $26.75 \%$ of the total homeless children and encountered by various challenges throughout the country. Taking the above fact into consideration, children who are living in Ambo town, as part of Oromia region are also among that number of homeless children and faced by different challenges. With this rationale, this research was conducted to identify the major challenges and coping strategies that are used by street children to resolve their challenges.

\subsection{Objectives of the Study}

The aim of this research study was conducted with the purpose of investigating and describing the effects and survival strategies of street children who are living in Ambo town.

\section{Research Method}

\subsection{Research Design}

The research method that was employed during this study was qualitative research approach. The justification for using method is that the research study was conducted in a single point in a time and was largely based on subjective interpretation of the participants. As (Nick, 2010) elaborated, qualitative research tends to be interpretive and seeks to understand a phenomenon in its context in greater depth. Moreover, it seeks to elucidate the nature of social practices, relationships and beliefs along with the meaning of human experiences from the participants' point of view.

Since the major interest of the researcher was to understand Effects of Street Children and to explore how they employ coping strategies to meet their challenges, the qualitative methodology which imparts phenomenological theory was chosen to conduct the research study. Because this qualitative approach allowed the researcher to access the personal experiences of the informants who frame, articulates and reveals life as experienced in a case structure. Realizing the benefits above, the researcher realized that this method is an exploration process to understand the phenomenon in its entirety, rather than just focusing on 
specific concepts. Hence this research, as a form of case study phenomenological inquiry aimed at capturing the lived experiences of street children. Thus since the study used exploratory qualitative approach, substantial data were collected, analyzed and interpreted in relation to the research questions and objectives.

\subsection{Sampling Techniques and Procedures}

The participants were selected using purposive sampling technique. The sample size for this study was 27 participants in which 17 of them were participated in an interview and 10 of whom were participated in focus group discussion. According to Creswell (2014), the sample size of qualitative research is largely determined by theoretical data saturation especially at a point during data collection stage where new participants do not any longer bring new data or additional insights to the research questions.

During sampling process, the participants that were excluded are: street children who are above 19 years of age, street children who are below 10 years of age, street children who have hearing problems and street children who are mentally retarded.

\subsection{Data Collection Techniques}

This study has triangulated different methods, sources and data in order to do away out of the major dilemma of research, absence of a single satisfactory method of empirical investigation. The researcher used and employed different data collection instruments in order to get relevant and sufficient data that were needed in the study. The method that the researcher highly employed was in-depth interview, Which was the primary technique used by the researcher to gather data using semi-structured questions.

According to Robert (2011) in-depth interviews are used by the researchers who want to get and understand the internal feeling of the participant about the phenomenon being studied. In this data gathering process, the researcher formed three separate interview group from the 17 interviewed street children. The identification of the participants was made based on their explanation capacity and understanding of their situation. The criteria that were used to select participants for in-depth interview are: street children who are above 10 years of age, they have been living on street for 12 months and street children who are able to understand and explain his situation. Accordingly, each interview was conducted in a particular place convenient to the participant. For the purpose of maintaining confidentiality, some children were requested to change the location to more secure place where they feel comfortable. Each in-depth interview lasted from 30 to 45 minutes. Key informant interview, Ambo town women and child affairs bureau and Police officials were interviewed to obtain diverse insights about the circumstances of street children.

Through focus group discussion of data gathering technique, the researcher planned to obtain relevant qualitative data, which encompasses the discussant attitudes, opinions and feelings. Selection of participants of FGD was done deliberately by enlisting street children 'on' who are living and working on the street for more than one year and who were between age ranges of 12-18. This group discussion consisted of one FGD with 10 discussants. This method was used to identify the general opinion and experiences of a group of street children, mainly about range of problems they encounter on the street and the coping strategies they use while living and working on the street. The discussion lasted for one and half hours. 
To facilitate the discussions, the researcher employed different communication techniques. These included, probing, clarifying, reflecting, paraphrasing and summarizing.

The researcher also applied observation method along exerting all the above methods of data collection to understand the life situation of street children. The areas where observation was seen include main market called Arada Gebeya, Menahariya area (bus station) where most street children spend their time roaming around the place.

\subsection{Data Analysis Technique}

Accordingly, after collecting the necessary data, checking completeness and consistency the results was fed into data obtained through different qualitative techniques so as to triangulate and make rich description. thematic analysis it was the most common form of analysis in this qualitative research. Accordingly, thematic data analysis procedure delineated by Braun and Clarke (2006) was used.

\subsection{Ensuring Trustworthiness}

Ensuring trustworthiness in qualitative research is not as easy as in quantitative studies as there are no standardized sets of procedures and numerical formulas in this case. Keeping in mind this fact however, there are certain precautions that could help in making sure the study is as trustworthy as possible. As stated by Yin (2004), insuring rigor is the most important part of especially the process of analysis. And he forwards three major ways to do so. Accordingly, the researcher has checked and rechecked the accuracy of the data by looking through the accounts of the respondents and the consistency throughout each interview. And this was also facilitated by the effort made during the interview to check the researcher has fully understood what the participant meant at times when this was not clear. The researcher has also made the out most effort to making the analysis thorough and complete as much as possible by following through each and every step of the chosen analytic procedure which resulted in providing the readers with sufficient amount of details ensuring the respondent's accounts were fully represented. The researcher has also made much effort to acknowledge any possible unwanted biases that could affect the process of analysis by stating her own personal thoughts and experiences related with the issue under study.

\section{Findings of the Research}

\subsection{Background of the Study}

This research was undertaken within the context and boundaries of Ambo town. The town is found in West Shoa Zone of Oromia National Regional State. It has a distance of $112 \mathrm{~km}$ from Addis Ababa and located between astronomical grids of $80^{\circ} 47^{\prime} \mathrm{N}-90^{\circ} 21^{\prime} \mathrm{N}$ and $37^{\circ} 32^{\prime}$ E-38 $30^{\prime} \mathrm{E}$ and it is the capital of West Shoa Zone. The total number of population residing in this town is 108,406 out of this total population, 54, 186 and 54, 220 are males and females respectively (CSA, 2007).

\subsection{Factors That Lead Children to Street Life}

The participants also elaborated on full factors that motivate them to join the life on street. These factors are: search for job, independence and freedom from familial control. Children go to the street in search for jobs to fulfill their unmet needs. Ayalew narrated his story as follows:

My name is Ayalew. I was born in Wolaita. My elder brother told me that there are plenty of 
good jobs in Ambo town. As a result I quit school and came here, but I eventually found out that there are no jobs at all that is why I end up selling lottery cards on the street. Ayalew elaborated further: Here I am facing a lot of challenges that are unbearable. Things have gone contrarily to what I wished. There are no jobs, and even getting food, place to sleep and clothes to wear become so challenging.

Obetsu who was also a participant of in-depth interview added his explanation as following:

I came to the street life some years back because I was looking for a job. I asked some friend who knew Ambo before and they told me that there are many good jobs in Ambo. I never attended school even when I was at home. My main motive is to work and get money.

Beldhuma also illustrated his condition as follow: My friends mobilized me from my rural village to come to Ambo town because it has better education. We established ourselves by renting a house, and we bought our school materials. After that we started our education and I completed one class here, but a year after I disagreed with them because they wanted us to move to Addis. I didn't want to go back home because my father and mother divorced. For that reason I joined other friends who were on the street. But not every street child end up on the street because of frustration of pre-anticipated advantages and positive life. According to some participants, some negative factors such as death of parents, living under guidance of abusive parent or relative coupled with lack of basic necessities move children to go to the street. Dagim illustrated his condition as follow: Both of my parents passed away and leaving me without somebody who looks after my needs. I moved from village and came here to Ambo, and I joined some group of friends. We are now living together. I work as shoeshine boy on the street so that I am able to earn money to cover my educational expenses.

Another participant expressed the abuse he experienced from his family that let him to live on the street as follow:

My name is Alemu, I previously live at home here in Ambo with both of my parents and siblings. My father is deaf and as a result, the administration of the family is taken over by my elder brother. We don't like each other. He always fights with me that is why I left home and live on the street with my other friends. Some participants joined street life because they experienced abuses and maltreatments from their own biological parents rather than from caretakers and relatives as the case is with the above participants. children favor the life of hardship on street more than living with abusive families. This was the case with the participant who narrated his expression as follow:

Mulu, reported that she stayed on the street for the last two years where she explained her reasons as follow: I quarreled with my father so I couldn't stay with him; my father beat me because I came home very late in the night and I ran away and joined the street life. Another girl Meseret, indicated her reason for joining the street in the following way: Both of my parents are blinds. They earn their livelihood through begging. I am the $6^{\text {th }}$ girl in the family. I couldn't agree with my mother. She always told me how much she hates me. She always used to tell me to go out from home. She didn't even want me to eat in the house. I have four brothers and five sisters. She didn't take care of me as my other sisters and brothers equally. I did not even have enough clothes and exercise books for my education. The insult and the cursing all damaged my feeling so much and forced me to join street life. Another participant 
narrated the abuses that force him to join the street as follow:

My name is Abdu. I came to the street because my mother always fights with my elder siblings and I am always afraid for that. One day while she was fighting with them, she asks me why I am just standing and watching them. She throws my clothes at me saying that go do not come back to me and I told her that I will never come back. That is how I get into street life. While the participants above reported that they left home and joined street life as a direct result of escaping abuse from unfavorable conditions from their parents, some reported that they left home because of commission of mistakes that their parents were not able to forgive them for.

This was the case with Zenebe who narrated that: My parents are poor and we live in a rental house. One day I broke the window of the house we rent. The landlord ordered my parents to pay for the window but they were not able to get such an amount of money. As a result they became angry at me and I escaped from them and live on the street.

As illustrated earlier, children join street life because of unforeseen negative consequences that may result from migration, the need for freedom from familial control, abuse by parents or guidance and sometimes as flight for offence they have committed at home. This was the case for some participants of this study. For examples Feyissa narrated his story as following: I have friends whom I always walk with. We would go somewhere and spend sometimes there. Slowly I started to stop from attending school. My mother was very angry at me. She beats me with an iron rod and she told me not to continue with my friends but I could not interrupt my relation with them. Finally I stopped going home and street becomes my living place.

\subsection{Problems Facing Street Children and Their Coping Strategies}

\subsubsection{Social Problems and Coping Strategies}

The major social problems that street children faces as mentioned by participants are verbal abuse, discrimination, physical abuse, negligence and negative attitudes of the police and society in general against them. Female children living on the street are more vulnerable to street life than their male counterparts due to gender-based violence and exploitation. Meseret explained the problems she faced as follow:

When I left home, firstly I went to work as a waitress in Ambo hotel. But I was fired after two months. I had no option but to go to the street. I thought on the street everything was easy but I found it very difficult and challenging. Especially because men mistreat female street girls so badly, they do many bad things. I was raped by 2 boys in several occasions. As a result, I passed through psychological trauma that lasted for a very long time. I also suffered from womb infection and I was also pregnant at that time but I was compelled to commit abortion because that was the only option I had. She illustrated her coping strategy to the social abuses she incurred on street as follow: The only way I use to cope with those problems is flight. I keep on changing my leaving environment. For example, I changed my sleeping place from market area and went to the place near Orthodox Church compound because it is somehow secure there but again I was attacked at several occasion by some people I do not know and I changed the place for an area around condominium near to the campus but it was not good for begging, because there are many police men in that area. Again I moved to the market and 
eventually I become prostitute like other girls there. It was so challenging; I was beaten and raped many times; they even cut my body and face with razor blade and I still have the scar on my face. At times some of them come in group and made intercourse and leave without paying; some of my friends were even picked up and kidnapped by them. So the street life was very challenging for me.

Even though street girls are more vulnerable to physical and sexual abuse and exploitation, male street children are also victims of sexual abuse. The focus group discussions with street children revealed that younger boys were raped by older male youths or adults living on the street. The participants also interactively discussed that they face continuous sexual abuse from younger adults living on the street, passengers and drunkards. In this case Adane who participated in FGD expressed his experience as:

I have been living on the street of different cities for the last 7 years. Seven years ago the street was not difficult but now a day things have changed and living on the street is very difficult. Among the difficult situations is male sexual abuse which is becoming common now. Once upon a time, while I was sleeping at night, I was almost raped by another powerful street boy due to that reason I was sick and had gone through psychological distress and serious physical injury. Ermias also a participant of FGD who came from Wolaita due to peer pressure and stayed on the street of Ambo for the last two years further added that: The street life challenge is diverse and very difficult. There were difficulties when I first joined the street to communicate with my friends. Before coming here I have never heard about sexual rape of male to male or homosexual intercourse. When I heard about it, I was shocked. Once I have also escaped from such incident with the help of my friends. He further explained his coping strategy to sexual assaults as follow: When street children live in a group or when they seem taught, no one dare to do any sexual assault or advance on them. That is why my strategy to protect myself from those predators is always to keep in a company of my village friends who we are now living together on the street. I never want to go alone. Another social problem encountered by street children is exposure to harmful use of substance. Street children are seduced to drug use as a result of fashion and showing of maturity while others engage in drug use as a mechanism of coping with different life challenges they face on the street. This was the case with Alemu a participant of in-depth interview, who illustrated that: Sometimes when I am depressed or stressed too much because of anything in my life on the street, the only method I use to cope with it is cigarette. I smoke cigarette and it excite me so that I forget any psychological distress I may be experiencing before. One participant of FGD confessed that he learned many bad habits after he joined the street and he was addicted to substance abuse like chewing chat, smoking cigarette and 'mastish' (inhaling glue). Due to this addiction habits he said he used to have bad behaviors like stealing, fighting with his friends and involving in violence (beating females). He also said that he was only worried for his addiction habits and for this he used to work car washing and carrying goods belong to other for payment especially on the market days.

Another most challenging social problem that street children face in their daily life is negligence and abuse such as intimidation, insulting, batting and grabbing of private properties by members of the public as a direct result of their negative attitude toward them. Achenafu narrated that People look at us as dirty. They don't see us like human being. They 
throw dirty water and sometimes urinate on us when we lay down sleeping on the floor at night. When it rains in the night, it is always unbearable but even if we go to seek shelter in the shaded areas of hotels and some government institutions, the security guards and polices always chase us away. Ayalew added that People verbally and physically abuse us especially when they see us roaming on the street. Sometimes they confiscate lottery cards from me by force and refuse to pay when they do not win anything from the cards. The owner of the lottery cards I am selling also abuses me. For instant he insult and force me to pay for cards which are grabbed from me by force but I have nothing to offer him. He added that the only coping strategy he uses to deal with abuse from members of the public is to accept any type of insult, name he is called at and physical abuses and to give in to their demand. This involve letting them go freely even incase that may motivate legal suit.

Obetsu stressed that the coping mechanism that I use to deal with social challenges such as abuse is by reporting the issue to the police. When somebody grabs my lottery card, the police help me by compelling them to pay back the fee, but also sometimes the police do nothing. In case of the situation where police is not available, I have nothing to do more than letting them go away with what they did to me because I have no power.

While participants of both in-depth interview and focus group discussion have presented that most of the social problems they face are as a direct result of negative attitude of the whole society toward them, a police officer who was a participant of key informant interview narrated that street children are also the causatives of some social problems. He stated described his feeling as follow:

Children on the street regardless of their age have a strong sense of unity and structure like those of criminal organizations. They are the one causing many social problems being faced here in Ambo town for example night robberies, vandalism and thefts.

\subsection{Economic Problems and Coping Strategies}

\section{A. Access to food}

According to the participants of this study, they get it hard to access food and even if they really get food, it is always not enough and is very poor in term of its quality. Ayalew narrated his food situation as follow: Food is not enough always for us here. Sometimes if you get breakfast you are lucky enough. In some days, you may spend the whole time without any food at all. Kidane added that I eat meal at any time I get it, but not always. Sometimes I spent the whole day without eating when I am not lucky, and sometimes I have a plenty when I get it. According to the information presented by the participants, getting food is not the same for them. Some of them reported that it is easy to get food while others such as Ayalew mentioned above feel that it is hard to get it. It is worth mentioning that the type of street child and his/her attitude determines his/her access to food. Some children work or engage in some business activities to get food and use other alternatives only when they have no option. Gadissa narrates how he gets food as following: I engage in all kinds of work especially on the market days. Whatever I earned from there I use it to buy for my food because it is not always enough, but whenever there is no any kind of work, I go to restaurants and beg for leftover food.

Obetsu, a street boy who said that I get some amount of money by selling of lottery cards to 
the buyers on the street. It is enough for me since I get what to eat from it. I get breakfast, lunch and dinner from it every day. I do not have anywhere else to get food apart from paying. Dagim, added that: When I firstly came to the street, I found out that it is difficult to get food to eat. But I thought and realize that I need to do something that will guarantee my meal. Then I asked my friends and they contributed some money. I opened this shoeshine center, and it gives us some money to pay for our food.

Some participants have also reported that left over food they beg from hotels and restaurants are what they always eat as their meal. Some beg for it while others get it freely yet some have to perform some work for restaurant owners such as cleaning dirt or emptying garbage boxes. Achenafu an in-depth interview participant narrated how he gets food from restaurants as follow: I get my food from restaurants only. Each time of the day I go there and beg for it. They give me if it is available and if not then I spend the day without any food at all. Zenebe added that In every morning I go to restaurants and hotels to beg for "Bulle" (yesterday's leftover food) but they don't give it freely. They always tell me to clean their dirt in exchange for Bulle. Even if they give, it is not always. If I am lucky enough and got breakfast that is enough for the whole day.

Some participants reported that people are very kind to them especially the elderly and women. They give them some food. Some invite them in hotels and restaurants during meal times. This was the case for Melkissa who narrated that Some people here are very kind to us. When they see us Hungry, they call us and buy some food for us. For example, in the morning we stand around Manaria (Bus station) and when it is time for breakfast they call us to have a meal with them. At the end they told us to go home and not to live on the street.

\section{B. Access to Housing}

Getting place to sleep is one of the most challenging problems reported by some participants. Street children like Zenebe live in tunnels along the major road of Ambo town. He reported that since his mother dismissed him from their home, tunnels and dishes have become his sleeping places. Melkissa explained that I have a blanket brought to me by my friend. I use it for sleeping inside the dishes on the road side near Maneria (bus station). It protects me from cold. But before that I used to sleep with my other friends.

Some participants reported that they do not have constant sleeping place. For example, Gadissa who was a participant of in-depth interview narrated that I sleep with my other friends. We roam the town throughout the night looking for sleeping place and we spend the night wherever we find suitable but most of the time around the main market. Alemu added that I do not have constant sleeping place. Today when I sleep here and someone else or the police came and chase me and my friends out, then we move and search for another places mostly dishes on the road sides.

Some participants reports that they live in a group of 2 to four. They collect dirty or thrown away sleeping mattresses and spread them in the tunnel as their bed sheets and use it for night times. Zenebe narrated as follow my sleeping places at night are the open holes. I sleep with my friends and we have two old mattresses that we collected from garbage center, and they are what we are using for sleeping during the night. Abdu added that: I don't have a house to sleep. I always sleep with my friends inside holes and water canals by the road sides. For 
example, that one on the road adjacent to the telecommunication office is our sleeping place now. We have two mattresses we collected from garbage plus old sleeping clothes and we are using it now. We were three inside there but one of us was taken back home by his brother's friend.

Some street children came out with different coping mechanisms. For example, participants who engage in paid labor activities and petty businesses reported that they rent some rooms in a group so that they use it for night times. This was the case with Obetsu who narrated that: I live around Kebele 07 with other street boys. We rented a house that accommodates all of us and by the end of the months each and every of us contribute his share of the rent. We are many and live in that room as a group especially those of us from Wolaita zone who sells lottery cards on the street here in Ambo. Ayalew who originally came from Wolaita also expressed that: Getting place to sleep in the night here in Ambo is problematic especially for street children. I live with my brother who came here in Ambo before me; we sleep in the house constructed by mats, but back home, I live comfortably with my relatives who provided for my needs and give me a good place to sleep.

Some participants reported that they developed a relationship with security guards of some public and private institutions and as a result, they get access to verandas and rooms where they use it to spend their nights. This was the case with Feyissa who narrated that: I and my friend spend the night with one security guard. He is very kind to us. When it rains, he would go to another room which is inside of the building and he would vacate his outside room for us. Beldhuma added that; previously getting place to spend the night was very difficult as a result we used to sleep by road sides but currently there is a man who owns a big restaurant. He becomes our friend and eventually allowed us to sleep in the veranda of his shop.

\subsection{Health Problems and Coping Strategies}

Street children in Ambo town are facing different health challenges, but as the participants of this research study reported, the health problems vary from individual street child to another. Most participants of both in-depth interviews and FGD reported that they have never felt sick for the last six to twelve months, while others who reported to have been sick with minor illness reported that they lack access to public health facilities and medical care yet some get medical treatment from private clinics.

According to the participants, the main health problems they face are headache, stomachache and malaria, Ayalew Explained his health situation as follow: My health situation here on the street is not good. Sometimes I feel ill for example because of malaria and other illnesses but it is even more difficult because I do not have proper medical care to get medicines. He went further by elaborating that:

Malaria, headache and stomachache are the main health conditions we have been facing. This is because of the poor living condition, nutrition and psychological state we are in. Asked how he gets medical service and coping strategies he use when there are no medical treatment in relation to his sickness, Ayalew narrated as follow: When I was at home in Wolaita, my family covers my health needs and expenses but now when I feel sick, my brother whom I am living with takes me to the nearby clinic where I get medication. Also the man I am working with by selling his lottery cards provides me with some medical services. He does not directly 
pay us money to go to clinics but brings medicines when any of us is ill. We do not get any free health care from public hospital. He elaborated that his only coping strategy is to stay at home sleeping when sick because he has nowhere to seek medical care. The participants of FGD narrated that those of them who are engaged in selling lottery cards get medical services and treatment from the owner of the cards they are selling. Although the quality of that service cannot be determined; the participants who are selected from that category of street children reported that when any of them feel sick, the owners of the cards bring him some medicines. The most health challenges that all of them reported are stomachache and malaria, Obetsu explained as follow:

As for now I am physically healthy, but sometimes I have stomachache. This is the main health challenge that I am facing. The man whose lottery cards I am selling on the street helps me when I am sick by bringing medicines from hospital, and I use it to cure my illness. Like Ayalewt, Obetsu also reported that the only coping strategy he use when he felt sick and his master did not bring him medicines is to sleep at home and wait for natural cure from almighty God. But some participants who are also engaging on street sale of lottery cards have different coping strategies for example; Gemechu who participated in an in-depth interview narrated that:

In most of the times, the man I am selling his lottery cards on the street gives me medicines when I am sick, but in a situation where he did not provide anything, the coping strategy I use is to go to private clinic and buy medicines using money I make from that business. This was the case with Kidane who narrated that: When I am sick, I do not go to any hospital. I just stay home and sometimes when I have some money on my hand, I go and buy drugs from private clinic. Some participants reported that they get access to health services in private clinic paid for by a compassionate individual. For example, Zenebe when asked about his health situation responded that: I am physically healthy now but last time I was ill and a man who felt compassionate took me to the hospital. We do not know each other before. He just got me on the street and took me to the hospital.

Some participants reported that they came up with different strategies to cope with health challenges they are facing. Among those strategies is cooperative work in which all of them look into health need of any member of their group by taking him to the hospital in case he does not feel well. This was the case with group of street children who live together with Abdu who was a participant of in-depth interview. He narrated that:

We collectively contribute whatever money is in our pockets and use it to take anyone among us who is sick to private clinic to get medicines. This is the same when I am also sick, but when there is no money in our pockets, that person sleep only.

\section{Discussion}

The data are discussed here thematically with information provided by the participants ordered logically in-line with interview questions and the theme it tries to cover. This was done in accordance with objectives of the study outlined.

Interview analysis of the primary data collected revealed that the reasons behind the initiation of participants to street life are violence and abuse at home, death of one or both parents, lack of support in case of orphan hood, poverty (inability to satisfy basic needs) and pressure 
created upon families due to poverty, family breakdown and family pressure to engage in work, commission of mistake, search for jobs, peer pressure and expectation of positive life as a result of freedom from familial control. The finding of this study according to the participants is inconsistent with previous studies which alleged that children in Ethiopia are pushed to the street in most of the time by poverty at home (MoLSA, 2004, FSCE, 2003 and UNICEF, 2012).

The research finding postulates that The participants of this study reported that they experience different kinds of social problems on the streets. These problems range from verbal abuse, physical abuse, sexual abuse, prostitutions, drug use, discrimination, prejudice and constant chase by the police. According to the female participants, these social problems are more sever to them than their male counterparts. They narrated that this is because of their vulnerability to rape and sexual exploitation. But some research participants who are male also explained that they are vulnerable to sexual assault and forced homosexuality especially by strong elder boys. The finding confirmed that the participants described different coping strategies they use to cope with social abuses they face on the street. But as we noted from the analyzation of the interview data, these strategies vary from individual participant to another. The main strategy that most participants reported to be using is flight or acceptance of abuse. Some participants reported that they use ignorance and silence especially when they are verbally or physically abused while others reported that they keep on changing their living environments to escape abuses, yet some participants reported that they use living in a groups as a coping strategies to thwart away abuses such as sexual exploitations. The finding is consistent with different studies on the social problems facing street children in Ethiopia (Adugna, 2006, FSCE, 2003, Girmay, 2007; Heinonen, 2000).

The participants during in-depth interviews and FGD reported that they find it difficult to get predictable source of food. They reported that one of the main continuing challenges in their daily street life is getting the food. Yet the participants reported that they use different strategies to get food. Among the strategies they reported to be using include: begging, collecting food from slum areas, begging for left over foods from hotels and restaurants, and engaging in remunerable labor activities to buy food. Participants also reported that they engage on petty street business such as selling lottery cards and shoe shining to serve as secure base for their access to food and other necessities. This is consistent with finding concluded from a study conducted with street children in Nekempte (Azmeraw, 2015).the finding from key informant interview with officer from South West Shewa Zone BWCA revealed that there were no efforts to help street children neither by governmental nor by nongovernmental organizations in Ambo town resulting into failure of implementation of the policies and programs of the government on the welfare of children.

The problem of housing and safe sleeping place remains challenge for the majority of the participants of this study. Some of them reported that they sleep in dishes, and tunnels along the main roads of Ambo town, while others reported that they have no constant sleeping place as a result, they keep on moving and searching for places to sleep. Participants narrated that they use different strategies to cope with the challenges relating to finding a safe place to sleep. Some of them reported that they sleep in rental dormitories in groups where as others reported that they developed friendship with some business owners and security guards of 
some public institutions in which they are permitted to sleep in verandas. The finding was consistent with the study conducted by (Tadele, 2009; Samuel, 2014; \&Abro, 2012), the higher proportion of street children sleep in slum areas, religious centers, verandas and in tunnels of major roads in urban centers.

\section{Conclusion}

The study was conducted with the objective of assessing the problems and coping strategies of street children in Ambo town. The finding of the research indicated that research participants are facing numerous social problems ranging from sexual abuse, verbal abuse, physical assault, rape, engagement in drug abuse. During the study, it was noted that, poverty alone was not seen as a sufficient factor that push children to the streets. Research participants mainly saw the pioneer factors as family disruption, such factors, as already noted above, included abusive families, living under the care of unloving caretaker, death of a primary care-giver, inadequate care and support. The attractive influence of city life, jobs and cultural demands were also identified as a cause for involvement of the participants on the street. Female children living on the street are more vulnerable to street life than their male counterparts due to gender-based violence and exploitation. They are highly exposed to rape and they are also forced to divert to commercial sex work when other survival options are limited.Thec finding revealed that children join street life because of unforeseen negative consequences that may result from migration, the need for freedom from familial control, abuse by parents or guidance and sometimes as flight for offence they have committed at home.The lack of proper living place is among numerous challenges encountered by street children those who are living in Ambo town. The study demonstrated that majority of street children in Ambo town are males some of which migrated from Southern Nations and Nationalities People's Regional State and some from Words near to Ambo town. The research finding indicated that the participants were exposed to different health challenges because of their living condition and inaccessibility to medical services.

\subsection{Social Work Implications}

The finding also indicated that there is no effort being undertaken by relevant institutions that are supposed to be working for the need and welfare of children in general and vulnerable children in particular. This is marked by lack of programs and activities that are in place to address the situation of children who are currently experiencing different challenges. These institutions which are supposed to be working with children include Social and Labor Affairs office, Children and Women Affairs office, Zonal administrations and other stake holders such as none governmental organizations. The finding of this study also imply that there is a need for new strategies that should be taken hand in hand between concerned actors to bring into attention and address the problems of street children in particular. This effort can be effectively implemented with the participations of professionals and experts who are equipped with scientific knowledge to work with children. In general, the finding of the study indicates that participants are facing various problems on the street. Thus, it is mandatory to address those problems through professionally guided intervention mechanisms. With this regard social work profession have the leading role to provide various services through different approaches. 


\section{Recommendations}

Based on the above findings and conclusions, the following recommendations were forwarded for further intervention.

There is a need for new strategies that should be taken hand in hand between concerned actors to bring into attention and address the problems of street children in particular.

The zonal Administration should also work to mobilize all the stakeholders within and outside of Ambo town.

There is a need for greater endeavors and commitment on the part of the government and non-governmental organization working with street children to implement policies and child care programs by devising different projects and programs.

\section{Reference}

Abro, A. A. (2012). The problem of street children: A sociological study of urban Sindh University of Karachi.

Adugna, G. (2006). Livelihoods and survival Strategies among migrant children in Addis Ababa. Norwegian university of science and technology (NTNU), Trondheim, Norway.

Azmeraw, Z. (2015). problems and coping strategies of street children in Nekemte town, a master's thesis submitted to school of graduate studies, Addis Ababa University

Braun, V., \& Clarke, V. (2006). Using thematic analysis in psychology, Qualitative research in psychology, University of West England, UK (pp. 77-1-101). https://doi.org/10.1191/1478088706qp063oa

Creswell, J. W. (2014). Qualitative inquiry \& research design: Choosing among five approaches. Los Angeles, CA: Sage.

Forum for Street Children in Ethiopia. (2003). The Situation of Street Children in Eight Major Towns in Ethiopia Addis Ababa

Girmay, K. B. (2007). The situation of street children in Adama town. A thesis presented to the school of graduate studies, Addis Ababa University, Ethiopia.

Heinonen, P. M. L. (2000). Anthropology of street children in Addis Ababa, Ethiopia. Durham theses, Durham University.

Mekonnen, M. (2011). Street children in Addis Ababa: Exploring Policy Framework for interventions, Addis Ababa, Ethiopia.

MoLSA. (2004). Ethiopians National plan of action for children, Addis Ababa, December 2004.

Nick, E. (2010). Research Method, a practical guide for social science, University of Leed, USA.

Rober, K. (2011). Qualitative research from state to finish, Gillford press, New York, USA

Samuel, A. (2014). Assessing effects of streets on the livelihood of street children: A case study of Kumasi, Ghana. Research on Humanities and Social Sciences, 4(9), 165-173.

Tadele, G. (2009). Unrecognized victims: sexual abuse against male street children in Merkato area, Addis Ababa, Ethiop. J. Health Dev., 23(3), 174-182. https://doi.org/10.4314/ ejhd.v23i3.53238 


\section{Macrothink}

International Journal of Social Work

ISSN 2332-7278 2019, Vol. 6, No. 2

UNICEF. (2012). The state of the children's in the world: Children in an urban world. New York, USA :United Nations Plaza.

Yin, R. K. (2004). Case Study Methods (A revised draft). Washington, DC, USA: COSMOS Corporation.

\section{Copyright Disclaimer}

Copyright reserved by the author(s).

This article is an open-access article distributed under the terms and conditions of the Creative Commons Attribution license (http://creativecommons.org/licenses/by/3.0/). 